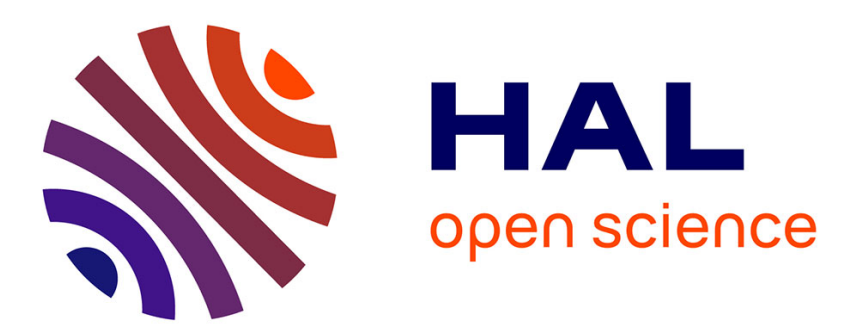

\title{
Simulation study of the timing of nitrogen fertilisation for young fruit trees
}

Patrice Loisel, Robert Habib, Daniel Wallach

\section{To cite this version:}

Patrice Loisel, Robert Habib, Daniel Wallach. Simulation study of the timing of nitrogen fertilisation for young fruit trees. Acta Horticulturae, 1992, 313, pp.81-88. 10.17660/ActaHortic.1992.313.9 . hal-02699408

\section{HAL Id: hal-02699408 https://hal.inrae.fr/hal-02699408}

Submitted on 1 Jun 2020

HAL is a multi-disciplinary open access archive for the deposit and dissemination of scientific research documents, whether they are published or not. The documents may come from teaching and research institutions in France or abroad, or from public or private research centers.
L'archive ouverte pluridisciplinaire HAL, est destinée au dépôt et à la diffusion de documents scientifiques de niveau recherche, publiés ou non, émanant des établissements d'enseignement et de recherche français ou étrangers, des laboratoires publics ou privés. 


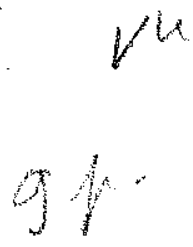

Number 313

October 1992

ISHS

International Society for Horticultural Science

\section{Third International Symposium on Computer Modelling in Fruit Research and Orchard Management}

Editors

J.G. Buwalda

T.A. Atkins 
SIMULATION STUDY OF THE TIMING OF NITROGEN FERTILISATION FOR YOUNG FRUIT TREES

$\begin{array}{lll}\text { P. Loisel } & \text { R. Habib } & \text { D. Wallach } \\ \text { INRA-Biométrie } & \text { INRA-Agronomie } & \text { INRA-Biométrie } \\ \text { BP 27 } & \text { BP 91 } & \text { BP 27 } \\ 31326 \text { Castanet Tolosan } & 84140 \text { Montfavet } & 31326 \text { Castanet Tolosan } \\ \text { France } & \text { France } & \text { France }\end{array}$

\section{Abstract}

In order to optimize nitrogen fertilisation, it is necessary to take account both of nitrogen uptake and of nitrogen redistribution within the plant. Quantitative mathematicil models of $\mathrm{N}$ uptake and partitioning have therefore been developed. The nitrogen uptake model describes uptake by peach trees during the first year of growth, in sand culture with continucus irrigation and $N$ fertilisation. Various candidate models were considered. In this case, the selected model used a third-order polynomial to describe root uptake efficiency. The partitioning model was developed using the same data set. The model describes nitrogen partitioning using a set of differential equations with transport coefficients. $\mathrm{N}$ uptake as calculated from thic uptake model provides the input of $N$. The transport coefficients were estimated by fitting the rnodel to the amounts of $\mathrm{N}$ in each plant compartment at each measured date. Given these two models, it is possible to calculate nitrogen fertilisation strategy to optimize various objective furctions. The present contribution focuses on this use of the modeis.

\section{Introduction}

For perennial crops such as fruit trees, there are two main sources of nitrogen nutrition. The first is soil nitrogen, taken up by the root system, and the second is nitrogen reserves in the perennial parts of the tree. In order to optimize nitrogen fertilisation, it is necessary to take acconnt both of nitrogen uptake and of nitrogen redistribution within the tres. Quantilative mathematical models of $\mathrm{N}$ uptake and partitioning have therefore been developort.

A dynamic simulation model of total nitrogen partitioning in a whole tree was doveloped by IIabib and Monestiez (1987). Nitrate absorption by roots was described by an cquation of the Epstcin-IIagen type (Epstein, 1976). Root uptake efficiency (g N/g dry roots/d) was assumed constant, with a value appropriate for a growing root system. The model was tested and modified for trees growing in soil (Habib et al., 1989). Wallach et al. (1990) slrowed that using a time-dependent function for nitrate uptake efficiency gives a model with smallcr iverage error of prediction for $\mathrm{N}$ uptake. The data set used in this study comes from peach trees cultivated in sand culture with continuous irrigation and fertilisation during the first year of growth. Habib et al. (1990) introduced the modified model for $\mathrm{N}$ uptake into the $\mathrm{N}$ redistribution model. This model then acceptably simulates $\mathrm{N}$ partitioning in the same peach trees referred tor) above. The model ignores $N$ redistribution from senescing leaves to the perennial parts of the tree. Since the data only go up to the start of leaf fall in the first year of growth this is not very important, but in a model covering several years of growth it would have to be considered. Given the timedependent uptake model and the partitioning model, it is possible to investigate the effects of various nitrogen fertilisation strategies. Given a criterion, it is then possible to calculate the optimum strategy. The present paper focuses on this use of the models. 'Tlue calculated strategics are in principle adapted to young peach trees, since the models are bisscel on results for such trees. But the method is suitable to a large scale of fertilisation problcms. 


\section{Materials and methods}

\subsection{Lay-out of The Experiment}

The experiment is fully described in Wallach et al. (1990) and Habib et al. (1990), and will thus only be briefly restated here. One-year old peach trees selected for similarity and severely pruned to increase homogeneity were planted on February 1985 in south eastern France in calibrated-sand containers. They were continuously irrigated and fertilised with a nearly constant nitrate concentration of $140 \mathrm{uM}$. Nutrients other than nitrate were applied as necessary, either in the irrigation water or in foliar sprays. At each of 13 dates starting midApril and ending mid-December 1985, randomly selected trees were removed from containers. Roots were extracted from sand, and each tree was divided into roots, trunk, shoots and leaves. Each part was oven-dried, weighed and analysed for total $\mathrm{N}$ content. Only the results up the start of leaf fall are used (i.e. 9 sampling dates ending 21 October 1985), since it was not possible to recover all fallen leaves.

\subsection{Modelling N Uptake (Wallach et al.,1990)}

The nitrogen uptake model describes uptake by peach trees during the first year of growth. In a first step, various candidate models were considered. All took the form of an Epstein-Hagen equation, with uptake rate expressed as the product of total root weight and root uptake efficiency. Each candidate model expressed the efficiency factor as a different order polynomial function of time. For each the mean squared error of prediction (MSEP; Bunke and Droge, 1984) integrated over time was estimated from the data. It was found that the model which expressed efficiency as a third order polynomial furction of time had the smallest estimated prediction error, and was therefore the model of choice. According to this model (Fig. 1), $\mathrm{N}$ uptake efficiency increases from near zero in mid-April to a maximun of $0.0031 \mathrm{~g}$ N. $\mathrm{g}^{-1}$ root. $\mathrm{d}^{-1}$ in late May, and then decreases again to near zero in late September.

\subsection{Modelling N Partitioning (Habib et al., 1990)}

The model describes nitrogen partitioning between plant organs using a set of differential equations with transport coefficients. $\mathrm{N}$ uptake as calculated by the uptake model provides the input of N. Four compartments are considered - roots, trunk, shoots and leaves. There are four main assumptions made in the model, (i) only certain of the flow pathways between compartments need be considered, (ii) for each compartment, the rate of nitrogen outflow depends on the nitrogen content of that compartment (i.e. its source capacity), (iii) the rate of nitrogen outflow from a compartment is proportional to the sum of the rates of dry matter increase in the compartments that can act as sinks for that compartment (i.e. sink needs for growth are considered the driving force for nitrogen partitioning), (iv) total outflow from a compartment is divided among the sink compartments according to their rates of dry matter increase (i.e. sink equivalence). The transport coefficients were estimated by fitting the model to the amounts of $\mathrm{N}$ in each plant compartment at each sampling date. Precisely, $\mathrm{N}$ partitioning is given by :

$$
\frac{d N_{i}}{d t}=a_{i} g(t)+\sum_{j=1}^{3}\left(\alpha_{i j} K_{j} N_{j}-\alpha_{j i} K_{i} N_{i}\right)
$$

where :

$$
g(t)=\sum_{k=1}^{4} \theta_{k}(t) g\left(t_{k}\right), \alpha_{i j}=\eta_{j i} \frac{1}{M S_{j}} \frac{d M S_{i}}{d t}
$$

and

$$
a_{i}=\frac{c_{0}}{K+c_{0}} M S_{1}(t) \frac{d M S_{i}(t)}{\sum_{l} d M S_{i}}
$$


and where $\eta_{i j}$ indicates a relation from compartment $i$ to compartment $j, \theta_{k}$ are the coefficients of the absorption function $g\left(\theta_{k}\left(t_{l}\right)=\delta_{k l}\right), c_{0}$ is the concentration of $N$ in the soil, $M S_{i}(t)$ is the dry matter in compartment $i$.

Given initial conditions, these equations are verified for $i=1,4$.

The criterion to minimize is a sum of squared errors :

$$
J=\frac{1}{2} \sum_{i=1}^{8} \sum_{i=1}^{4}\left(N_{i}(t)-N_{i}^{m}(t)\right)^{2} \delta\left(t-t_{i}\right)
$$

where the unknowns are the $g\left(t_{k}\right)$ for $k=1$ to 4 and the $K_{i}$ for $i=1$ to 3 .

$\left(N_{i}\right.$ and $N_{i}^{m}$ are the calculated and the measured values of $N$ in the compartment $i$ )

This was minimized using a Quasi-Newton method. We solved the adjoint system from $t_{\text {t }}$ to $t_{i}:$

$$
-\frac{d p_{i}}{d t}=\sum_{j=1}^{3} \alpha_{j i} K_{i}\left(p_{j}-p_{i}\right)+\sum_{i=1}^{8}\left(N_{i}(t)-N_{i}^{m}(t)\right) \delta\left(t-t_{i}\right)
$$

witl $p_{i}\left(t_{\jmath}\right)=0$ for $i=1,4$

and where $\delta$ is the Dirac function $\left(\int f(t) \delta(t) d t=f(0)\right)$.

and we applied the maximum principle of Pontryagin (Pontryagin et al, 1962) to obtain the derivatives of the criterion to minimize :

$$
\frac{\partial J}{\partial g\left(t_{k}\right)}=\int_{t_{i}}^{t_{j}} \theta_{k} \sum_{i=1}^{4} a_{i} p_{i} d t
$$

and

$$
\frac{\partial J}{\partial K_{j}}=\int_{t_{i}}^{t_{j}} \sum_{i=1}^{4} \alpha_{i j} N_{j}\left(p_{i}-p_{j}\right) d t
$$

\subsection{Optimization of the Timing of $N$ Fertilisation}

Given these two models, it is possible to calculate nitrogen fertilisation strategy to optimize various objective functions. Various objective functions, and various sets of possible strategies, may be of interest. For example, one can fix the total amount of fertilisation, and calculate the timing that maximizes the amount of $\mathrm{N}$ at the end of the season in roots or stem, in order to maximize reserves for the following year. Alternatively, one can maximize the amount of $\mathrm{N}$ in the leaves, in order to maximize the current growth. In the case considered here, the goal is to maximize the amount of $\mathrm{N}$ in the trunk at the end of the season. The total amount of fertilisation and the dates of fertilisation are assumed fixed (there are 10 dates evenly distributed over the season at $54,73,92,111,130,149,168,187,206,225$ days from planting). The trees are assumed to be growing in $0.1 \mathrm{~m}^{3}$ nutrient solution, renewed at each fertilisation. The optimization calculates the concentration of $\mathrm{N}\left(\mathrm{mg} . \mathrm{l}^{-1}\right)$ in the nutrient solution at each fertilisation date.

Precisely the objective function to maximize is :

$$
J=N_{2}\left(t_{f}\right) \text { (N in the trunk) }
$$

under the constraints of positivity for $N_{i}$ at each time $t$ and compartment $i$

The same model as the partitioning model was used for the optimization of the timing of $\mathrm{N}$ fertilisation except that :

$c_{0}$ is replaced by $N_{u} / v_{0}$, where $N_{u}$ is the amount of $N$ in the nutrient solution and $v_{0}$ is the reference volume:

$$
N_{u}(t)=u_{i}-\sum_{i=1}^{4}\left(N_{i}(t)-N_{i}\left(t_{i}\right)\right)
$$


Here the unknowns are the 10 amounts $u_{i}$. Therefore, we solve 10 systems (for each of the 19 days-period).

Three levels of total $\mathrm{N}$ fertilisation $N_{u}^{t}$ are considered, $10,7.5$ and $5 \mathrm{~g} \mathrm{~N}$. The optimization has been made under the constraint of a minimum value of $\mathrm{N}$ concentration in roots and/or leaves $t n_{i}$ : roots 0.01 and $0.011 \mathrm{~g} \cdot \mathrm{g}^{-1} \mathrm{~N}$, leaves $0.02,0.025$ and $0.026 \mathrm{~g} \cdot \mathrm{g}^{-1} \mathrm{~N}$. The optimization uses a Quasi-Newton method.

\section{Results and discussion}

The timing of nitrogen fertilisation for three levels of total $\mathrm{N}$ fertiliser (i.e. $10,7.5$ and $5 \mathrm{~g}$ $\mathrm{N})$ is shown in Fig. 2.

The overall pattern is a sharp increase in the amount of $\mathrm{N}$ fertiliser from the beginning of spring till the end of July, a decrease during the end of summer and then a stabilization at lower but significantly non-zero values during the beginning of autumn. This indicates that the $\mathrm{N}$ fcrtiliser is poorly used during the early spring, but is still useful during the autumn, what is consistent with a lot of published results. Although the timing of $\mathrm{N}$ fertilisation seens to be similar to the dynamics of $\mathrm{N}$ uptake efficiency (Fig. 1), the maxima are not reached at the same time (Fig. 3). This is most probably because the need for fertiliser is a compromise between the nitrogen uptake efficiency, the actual length of the growing root system and the nitrogen need for growth.

In terms of timing, there are only very slight differences between the three simulated treatments, and at each fertilisation date the partitioning of nitrogen fertiliser between treatments is almost proportional to the total amount of fertiliser in each treatment. However, the total amount of fertiliser affects the total amount of the taken up nitrogen. At the end of the sinulation period, the total amount of $\mathrm{N}$ in roots, trunk and leaves is about $85 \%$ and $63 \%$ of the $10 \mathrm{~g}$ fertiliser treatment, respectively for the 7.5 and $5 \mathrm{~g}$ total fertiliser treatments. Thus the decrease in nitrogen uptake has been less than the decrease in nitrogen fertilisation leading in a higher efficiency of $\mathrm{N}$ fertiliser.

For a total fertiliser amount of $10 \mathrm{~g}$, the figures 4 and 5 show the effects of various constraints on leaf $\mathrm{N}$ concentration on the timing of $\mathrm{N}$ fertilisation for a constraint of 0.010 (Fig. 4) and of 0.011 (Fig. 5) on root nitrogen concentration. For the lower root constraint (Fig. 4), the 0.025 and 0.026 constraints give the same results in terms of timing of fertilisation.

This means that the higher leaf constraint (i.e. 0.026 ) is not reached even when the 0.025 leaf constraint is used. More nitrogen is needed during the first part than during the second part of the growing season to meet these two higher constraints as compared to the lower leaf constraint (i.e. 0.020 ). This emphasizes the effect of the timing of nitrogen fertilisation on the dynamics of internal nitrogen. To reach a higher leaf nitrogen concentration it is necessary to achieve a higher nutrition level during the first phase of the growing season.

Although the differences between treatments (i.e. leaf constraints) are less marked for the higher root constraint (Fig. 5), the reverse result is obtained.

The 0.020 and 0.025 constraints give the same results while the 0.026 leaf constraint is different in terms of timing of fertilisation. This emphasizes the non-linear response of the uptake-partitioning model when the objective function is optimized to calculate the timing of $\mathrm{N}$ fertilisation.

Given two constcaints on leaf $N$ concentration (i.e. 0.020 and 0.025 ), the figure 6 shows the effect of two total amounts of $\mathrm{N}$ fertiliser on the timing of $\mathrm{N}$ fertilisation. When the lower total amount is used (i.e. $7.5 \mathrm{~g}$ ), the two leaf constraints are only slightly different in terms of timing of fertilisation.

At the contrary, they differ significantly when the higher total amount of fertiliser is used (i.e. $10 \mathrm{~g}$ ). This emphasizes the fact that the strategy of $\mathrm{N}$ fertiliser use is dependent on the total amount of available fertiliser.

In terms of modelling, this simulation study has shown that the same objective functions with various constraints can be meet with different amounts of total $\mathrm{N}$ fertiliser. Nevertheless, in some cases the optimization was not successful. For instance, the two higher leaf constraints (i.e. 0.025 and 0.026 ) could not be followed when the lower amount of $\mathrm{N}$ fertiliser was used (i.e. 
$5 \mathrm{~g})$. Moreover, the $\mathrm{N}$ concentration in the tree organs are not independent, they are coupled through the partitioning model. For example, a high root $\mathrm{N}$ concentration is not possible witl a low leaf $\mathrm{N}$ concentration. Thus, this is to be accounted for when one is to use this simulation technique to optimize some actual fertilisation strategy.

The case study used here for simulation was an hypothetical tree growing in nutrient solution. It is worth noting that the same modelling approach can be used for various plants even if the partitioning model has to be adapted to the specific plant under consideration. Furthermore, if a 'soil' model is available to simulate the transfer of nitrate-nitrogen in the soil profile, the same approach can be used with environmental objective functions, such as to calculate the timing of fertilisation which minimizes the leaching of nitrate under the root zone in order to prevent the nitrate pollution of the ground water.

\section{References}

Bunke O., Droge B., 1984. Estimators of mean squared error of prediction in linear regression. Technometrics, $26,145-155$

Epstein E., 1976. Kinetics of ion transport and the carrier concept. In Encyclopedia of Plant Physiology, Luttge W. (Ed.), Springer Verlag (Berlin), 2B, 70-94.

Habib R., Monestiez P., 1987. Modélisation de la dynamique de répartition de l'azote chez un jeune arbre fruitier pendant la phase de croissance exponentielle. I. Etablissement du modèle. Estimation des paramètres. Agronomie, 7, 401-408.

Ilabil, R., De Cockborne A.M., Monestiez P., Lafolie F.,1989. An experimental test of a nitrogen uptake and partitioning model for young trees. Tree Physiology, 5, 403-421.

Ilabib R., Loisel P., Wallach D., 1990. Modelling nitrogen partitioning in young trees during the first year of growth. In "II International Symposium on Computer Modelling in Fruit Research and Orchard Management", Logan (Utah, USA), September 5-8, 1989, Acla IIoriculturae, vol. 276, in press.

Pontryagin L.S., Boltyanskii V.G., Gamkrelidze R.V., Mischenko E.F., 1962. The mathematical theory of optimal processes. J. Wiley and Sons (Ed.), New-York, 360 p.

Wallach D., Loisel P., Goffinet B., Habib R., 1990. Modelling the time dependence of nitrogen uptake in young trees. Agronomy Journal, vol. 82, No 6, 1135-1140, 1990. 
g $\mathrm{N} / \mathrm{g} \mathrm{dry} \operatorname{root} s / \mathrm{day}$

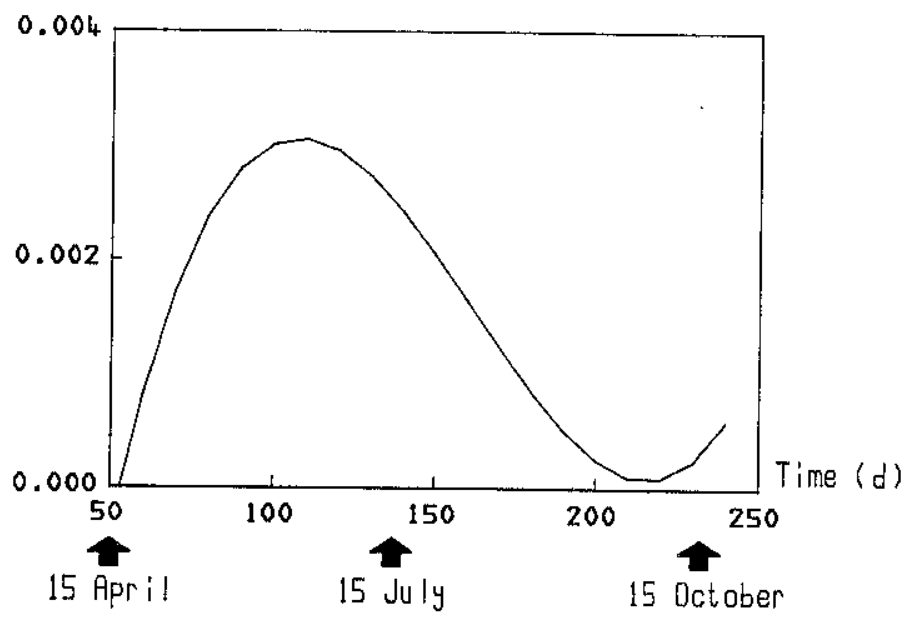

Fig. 1 : Time dependence of $N$ uptake efficiency

(from wallach et al., 1990)
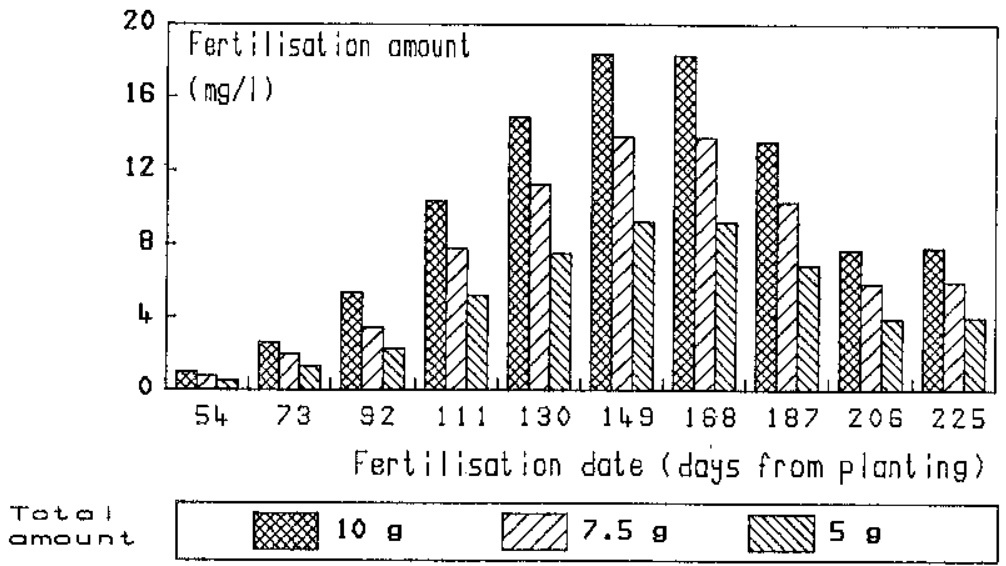

Fig. 2 : Timing of $N$ fertilisation for three levels of tatal $N$ amount 


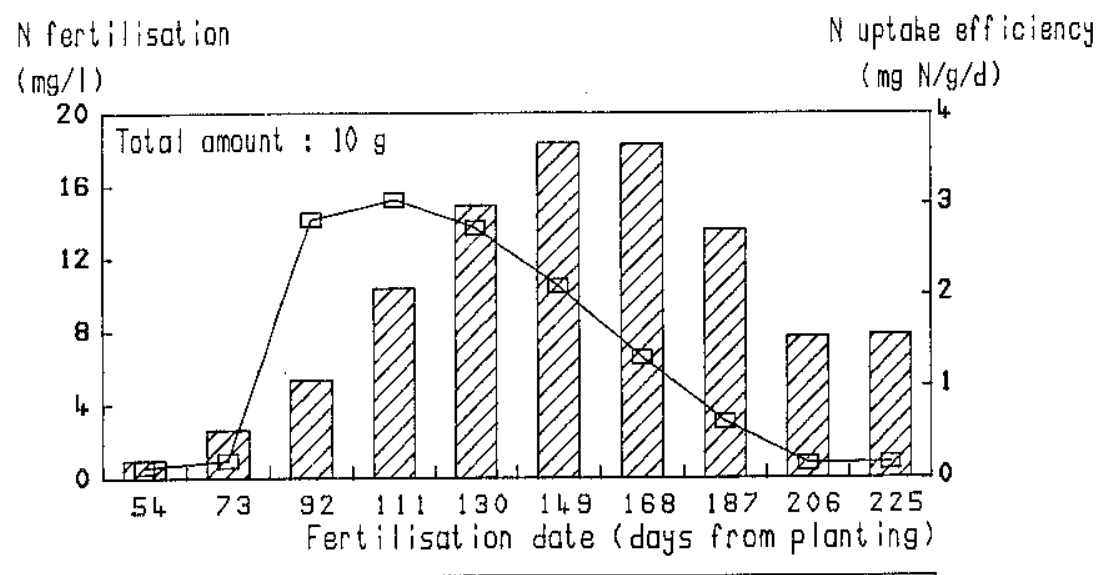

Fig. 3: Timing of $N$ fertilisation and dynamics of $N$ uptake efficiency

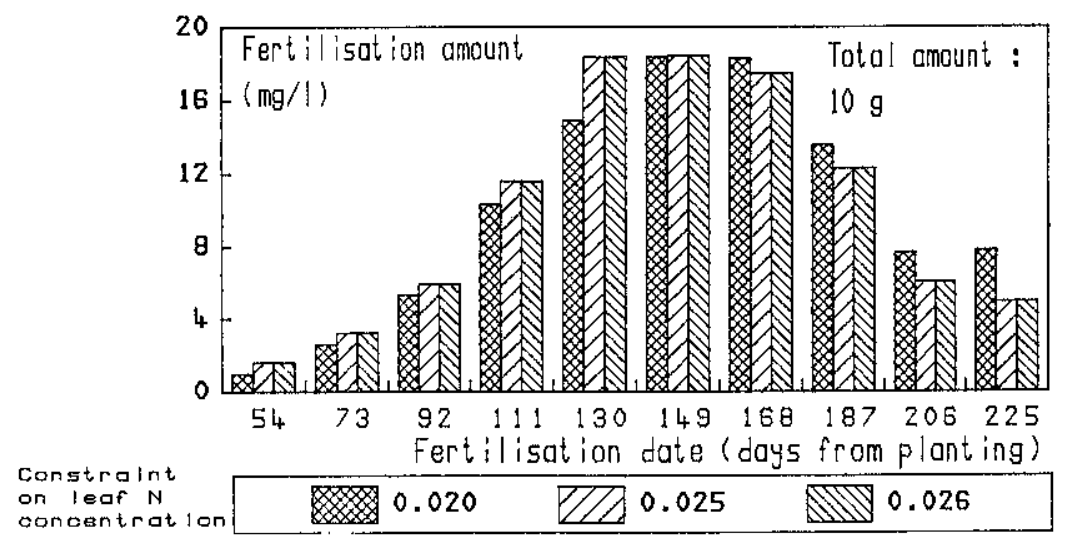

Fig. 4 : Timing of $N$ fertilisation for three constraints on leaf $N$ concentration (minimum constraint on root $N: 0.010$ ) 


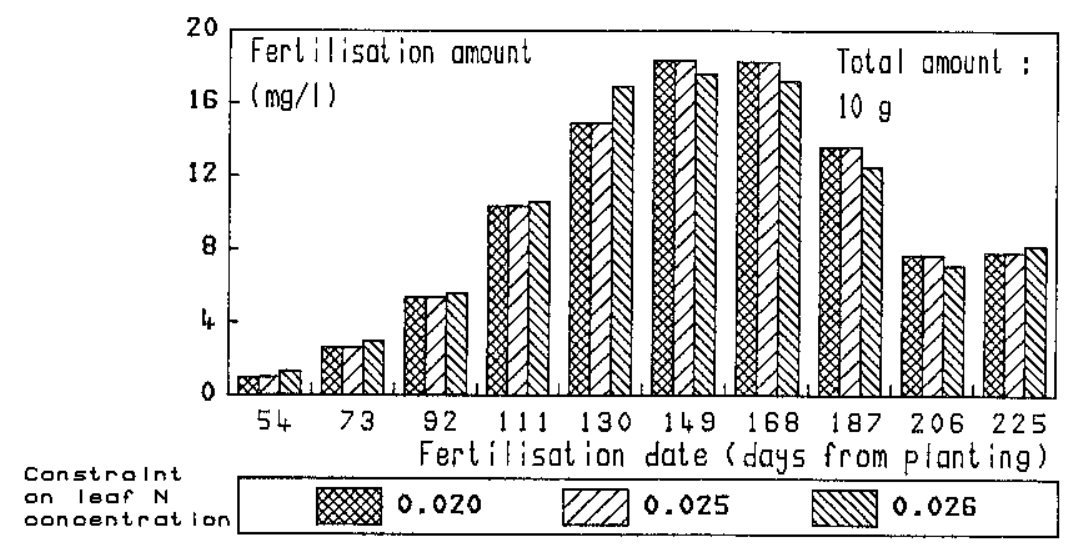

Fig. 5 : Timing of $N$ fertilisation for three constraints on leaf $\mathrm{N}$ concentration (minimum constraint on root $N: 0.011$ )

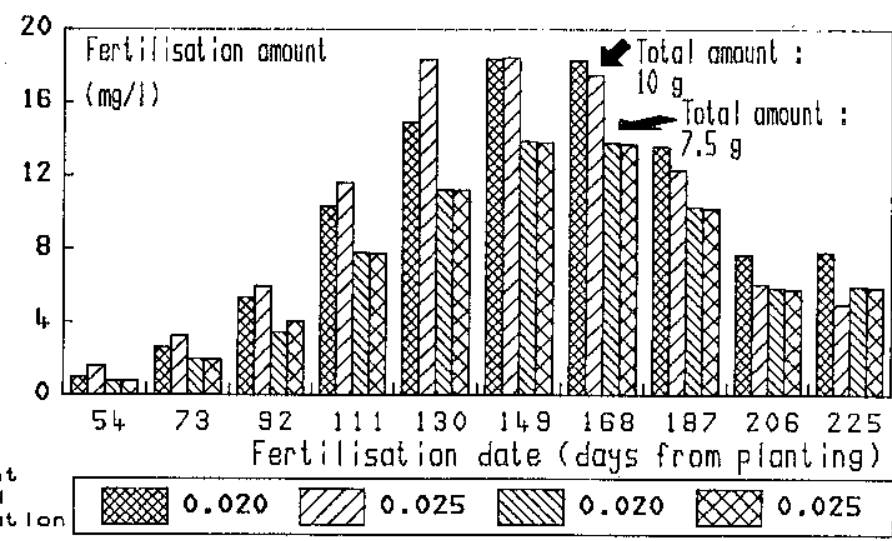

Fig. 6: Timing of $N$ fertilisation for two constraints on leof $N$ concentration and total $N$ amount (minimum constraint on root $N: 0.010$ ) 